\title{
A desertificação no Alto Sertão de Sergipe/Brasil: abordagem na perspectiva das vulnerabilidades socioambientais
}

\author{
Desertification in high Sergipe Sertão / Brazil: approach the \\ perspective of environmental vulnerability
}

\begin{abstract}
Alberlene Ribeiro de Oliveira ${ }^{1}$, Josefa Eliane Santana de Siqueira Pinto ${ }^{2}$ \& Francisco de Assis
Mendonça ${ }^{3}$

RESUMO

A desertificação é um dos cenários de degradação que repercute em todo sistema socioambiental. Tem origem na dinâmica natural e nas ações antropogênicas, visto que a natureza passa a ser explorada de forma exacerbada pela racionalidade econômica, dilapidando mais do que preservando, o que intensifica a crise ambiental. As áreas vulneráveis a desertificação são as que apresentam maior fragilidade climática (distribuição pluvial de forma irregular, ocorrência de precipitações torrenciais e/ou períodos muito secos); solos rasos propensos à erosão, mudanças de organização e de produção espacial (enfraquecimento econômico e emigrações) pelas atividades humanas. Nesse sentido, o objetivo de se desenvolver esta pesquisa é compreender os processos de vulnerabilidades a desertificação no Alto Sertão de Sergipe, tendo por base uma bibliografia pertinente ao tema e levantamentos de campo na área de estudo. No Alto Sertão Sergipano a desertificação é dinâmica e se desenvolve sobre um ecogeossistema frágil, cuja vulnerabilidade é aqui analisada sob o enfoque geográfico.
\end{abstract}

Palavras-chave: Natureza; Sociedade; Vulnerabilidade; Desertificação.

\begin{abstract}
Desertification is the degradation of the scenarios that impact the environmental system. It is originated through natural dynamics and anthropogenic actions, as nature is exploited by extreme economic rationalities under a squandering logic, which intensifies the environmental crisis. The vulnerable areas to desertification are those with greater climate fragility (irregular rainfall distribution, occurrence of heavy precipitation and / or very dry periods); shallow soils prone to erosion, changes in spatial organization and economic production (economic weakening and emigrations). In this sense, this research tries to understand the processes of vulnerability to desertification in Alto Sertão of Sergipe, based on relevant bibliography and field-work data collected in the area of study. In Alto Sertão Sergipe desertification is dynamic and develops over a fragile eco-geosystem, It's vulnerability is analyzed through a geographic focus.
\end{abstract}

Keywords: Nature; society; vulnerability; Desertification.

Recibido el 29 de septiembre de 2016, aceptado el 28 de noviembre de 2016.

1 A Coordenação de Aperfeiçoamento de Pessoal de Nível Superior (CAPES).

Grupo Geoecologia e Planejamento Territorial- GEOPLAN-UFS. Av. Marechal Rondon, S/N, Polo de Gestão/ Pós-Graduação, sala 01. CEP: 49100000 São Cristóvão, SE. alberlenegeo@hotmail.com

2 Departamento de Geografia, Núcleo de Pós-Graduação em Geografia NPGEO/UFS

3 Departamento de Geografia/LAOVCLIMA-UFPR, Pesquisador 1A/CNPQ. 


\section{INTRODUÇÃO}

Os processos de desertificação representam cenários de vulnerabilidade socioambiental, associados ao clima e as derivações antropogênicas. Mendonça (2010) reforça a ideia dos processos naturais (climáticos) e antrópicos envolvidos neste processo e destaca a ideia de CONTI (1995), quando explicita que ao contrário do que se possa pensar, a desertificação não é um fenômeno que se passa somente ao nível do clima; também o é no sentido ecológico.

Com efeito, as alterações na natureza tornaram-se mais intensas com o rápido crescimento dos processos de industrialização e urbanização, ao mesmo tempo em que promove o progresso tecnológico/científico, reflete nas relações do homem e nas relações deste com a natureza.

Neste interim, CONTI (1995) afirma que a utilização inadequada de alguns recursos naturais fundamentais à vida tem provocado um processo de transformação da natureza que conduz à degradação ambiental, a qual resulta, dentre outros fatores, do maior poder de intervenção do homem no meio ambiente, decorrente do desenvolvimento científico e tecnológico, do crescimento populacional e do aumento no consumo provocando, consequentemente, o empobrecimento dos ecossistemas e propiciando a desertificação.

LIMA et al. (2007) enfatiza que a presença do homem concretamente como ser natural e, ao mesmo tempo, como alguém oposto à natureza, promoveu/ promove profundas transformações na natureza mesma e na sua própria natureza.

Desse modo, a exploração exacerbada da natureza a partir do desmatamento indiscriminado e agropecuária extensiva pode levar ao desequilíbrio ambiental, promovendo o desgaste físico, químico e biológico do solo, em face o desencadeamento dos processos de degradação e/ou desertificação. A natureza passa ser um meio de produção de mercadoria que pode gerar uma crise ambiental.

BATISTA \& CONCEIÇÃO (2012) explicitam que a busca pela reconexão sociedade-natureza seria uma das relevâncias no fenômeno da crise ambiental actual. Esta crise convoca, para um debate científico e filosófico acerca do comportamento humano e sua relação com o meio ambiente.

As atividades antrópicas associadas às alterações na periodicidade da sazonalidade climática atuam como significativas para potencializar manifestação do processo de desertificação. PINTO (2007) enfatiza que a desertificação, portanto, pode resultar de mudanças climáticas determinadas por causas naturais ou da pressão das atividades humanas em ecossistemas frágeis.

Nesta perspectiva, o território semiárido do Alto Sertão de Sergipe apresenta-se com áreas de explicita susceptibilidade à desertificação, representando cenários de vulnerabilidades socioambientais, mediante a interação de processos naturais e antrogênicos.

Destarte, a vulnerabilidade surge em diferentes escalas nos territórios e que podem ser afetados de modos distintos, com capacidades e respostas desiguais perante problemas semelhantes. Desse modo, a presente pesquisa tem como objetivo compreender os processos de vulnerabilidades à desertificação no Alto Sertão de Sergipe, posto que ali se materializam vários indicadores de degradação da natureza e da sociedade que, conforme bibliografia específica indicam a instalação de tal problemática socioambiental. 


\section{Vulnerabilidade à desertificação e suas questões conceituais}

No contexto Geográfico o termo Vulnerabilidade está relacionado a dimensões física, ambientais, sociais e econômicas. Segundo CUNHA et al. (2006) a vulnerabilidade resultaria de um agregado de condições e/ou características, em várias dimensões, que acionadas em conjunto, ou mesmo de maneira individual, podem tornar-se elementos capazes de aumentar a capacidade de resposta aos efeitos de fenômenos (estruturais ou conjunturais) que afetam as condições de bem-estar.

Nas áreas onde ocorre vulnerabilidade revela a fragilidade de um sistema e a sua competência para superar a anormalidade provocada por um evento possível, trazendo consequências tanto para as populações, como para seus bens, pois afeta o funcionamento destas e do ecossistema.

O Alto Sertão de Sergipe, foco de análise de estudo, apresenta fragilidade ambiental e limitadas condições de autocontrole frente à instalação de processos transformadores.

HOGAN (2005) destaca dois aspectos importantes do termo vulnerabilidade: a vulnerabilidade do lugar e a vulnerabilidade de grupos sociais. O primeiro está relacionado aos riscos ambientais presentes no lugar, o que o torna vulnerável ambientalmente. Já o segundo revela as relações entre os impactos sociais e ecológicos das mudanças ambientais sobre as pessoas.

A vulnerabilidade ambiental é vista como áreas de riscos que acabam gerando problemas ambientais e consequentemente social e econômico, tais como desertificação, seca, enchentes, tempestades, dentre outros.

A desertificação representa um dos processos de degradação ambiental que mais afeta a estrutura e o funcionamento das terras, podendo provocar ou acentuar o intemperismo e a lixiviação dos solos, desestabilizando o equilíbrio da natureza. Nesse sentido, ALMEIDA et al. (2001), explicita que a desertificação constitui todo um conjunto de processos que promovem o desequilíbrio dos meios físico, químico, biológico e socioeconômico e que voltamse no sentido da exaustão ambiental. Desertificação possa induzir a crer, ela não constitui a formação ou ampliação de desertos.

LIMA et al. (2007) compreendem que a desertificação é decorrente de variações climáticas e atividades humanas. Nimer (1980) reforça a ideia que, embora muitas causas dê origem à desertificação, estas podem ser determinadas por dois fatores: mudanças de clima, caracterizada principalmente por uma crescente deficiência de chuvas, e a ação do homem.

Emvirtudedareduçãooudodesaparecimento da cobertura vegetal, o balanço térmico ao nível da superfície desequilibra-se, com aumento da refletividade, da radiação solar, ou seja, do índice de albedo. Este, por sua vez, intensifica a subsidência atmosférica, conduzindo para a superfície o ar seco da alta troposfera, inibindo a formação de nuvens. Da mesma forma, o solo desprotegido e exposto diretamente à radiação solar tem seu armazenamento d'água comprometido (PINTO 2007).

Essas mudanças na estrutura dos sistemas naturais e sociais poderão tornar um cenário de vulnerabilidade levando a ocasionar a desertificação. NAVARRETE et al. (2007) propõem que a vulnerabilidade é um atributo de um sistema (e portanto, podemse distinguir áreas que são vulneráveis de áreas que não são), que se mantém exposto a uma perturbação e ainda assinalam que um sistema pode ser vulnerável a uma determinada perturbação, e não sendo vulneráveis a outros.

Nesse sentido, MENDONÇA (2010) aborda que a heterogeneidade espacial e temporal das condições climáticas 
introduz, de maneira clara, a compreensão de que os riscos e as vulnerabilidades socioambientais das sociedades em face das mudanças climáticas não são homogêneos, ou seja, de que as sociedades e os lugares serão diferentemente impactadas pelos eventos climáticos de caráter extremo ou catastrófico.

SOUZA (2000), com base em critérios de TRICART (1997) propôs a definição de vulnerabilidade, nos estudos da dinâmica ambiental para o Estado do Ceará, observando as interferências dos processos morfogenéticos e pedogenéticos, do estado de evolução das unidades geoambientais. Para esse modelo de classificação é utilizada a seguinte tipologia:

Ambientes estáveis: apresentam estabilidade morfogenética antiga em função da fraca atividade do potencial erosivo. Os processos morfogenéticos e pedogenéticos possuem um balanço favorável à pedogênese, o recobrimento vegetal é pouco alterado pelas ações antrópicas, ou existe franca regeneração da cobertura secundária, a qual evolui para as condições próximas as originais, existindo um equilíbrio entre os fatores do potencial ecológico e os de exploração biológica.

Ambientes de transição: a dinâmica atual do ambiente é marcada pelo predomínio de processos morfogenéticos ou processos pedogenéticos, o que pode favorecer uma ou outra condição: onde predomina a pedogênese favorece aos meios estáveis; e onde predomina a morfogênese, favorece aos meios instáveis.

Ambientes fortemente instáveis: apresenta uma intensa atividade do potencial erosivo com nítidas evidências de deterioração ambiental e da capacidade produtiva dos recursos naturais, o que pode comprometer as reservas paisagísticas. $\mathrm{O}$ balanço entre a morfogênese e a pedogênese é favorável à morfogênese.

\section{MÉTODOS E TÉCNICAS}

Os municípios do Alto Sertão de Sergipe (Fig. 1), objeto de estudo localiza-se a noroeste do Estado de Sergipe, abrange uma área de 4.908,20 km², sendo formado por sete municípios (Canindé de São Francisco, Poço Redondo, Monte Alegre de Sergipe, Porto da Folha, Gararu, Nossa Senhora de Lourdes e Nossa Senhora da Glória), e apresenta com fragilidade ambiental que repercute em todo sistema natural e na qualidade de vida da população.

Estes municípios estão inseridos nas Áreas Susceptíveis à Desertificação (ASD) do Semiárido Brasileiro; tal delimitação foi publicada, em 2004, pelo Ministério do Meio Ambiente/Secretaria de Recursos Hídricos no Programa de Ação Nacional de Combate à Desertificação e Mitigação dos Efeitos da Seca (PAN-Brasil - BRASIL, 2005).

A elaboração deste trabalho se estabeleceu a partir de levantamento bibliográfico com base em uma literatura pertinente ao estudo da pesquisa que auxiliaram como embasamento teórico.

Foi realizado trabalho de campo nos municípios do Alto Sertão de Sergipe, nos dias sete a onze de Dezembro de 2015, onde foram observadas sistematicamente as prováveis degradações ambientais relacionadas ao uso e ocupação do solo e criou-se o quadro síntese.

Como apoio ao trabalho de campo foi utilizado o GPS (Sistema de Posicionamento Global), no qual todos os pontos visitados foram georreferenciados e também foi confeccionado mapa da área de estudo, para tanto, foi utilizada a base cartográfica do Atlas Digital Sobre Recursos Hídricos do Estado de Sergipe/SEPLAN/SRH-2012, assim como o Sistema de Processamento de Informações Georreferenciadas na versão do ArcGis 10.2.1 e suas extensões para geração do banco de dados digitais georreferenciados. 


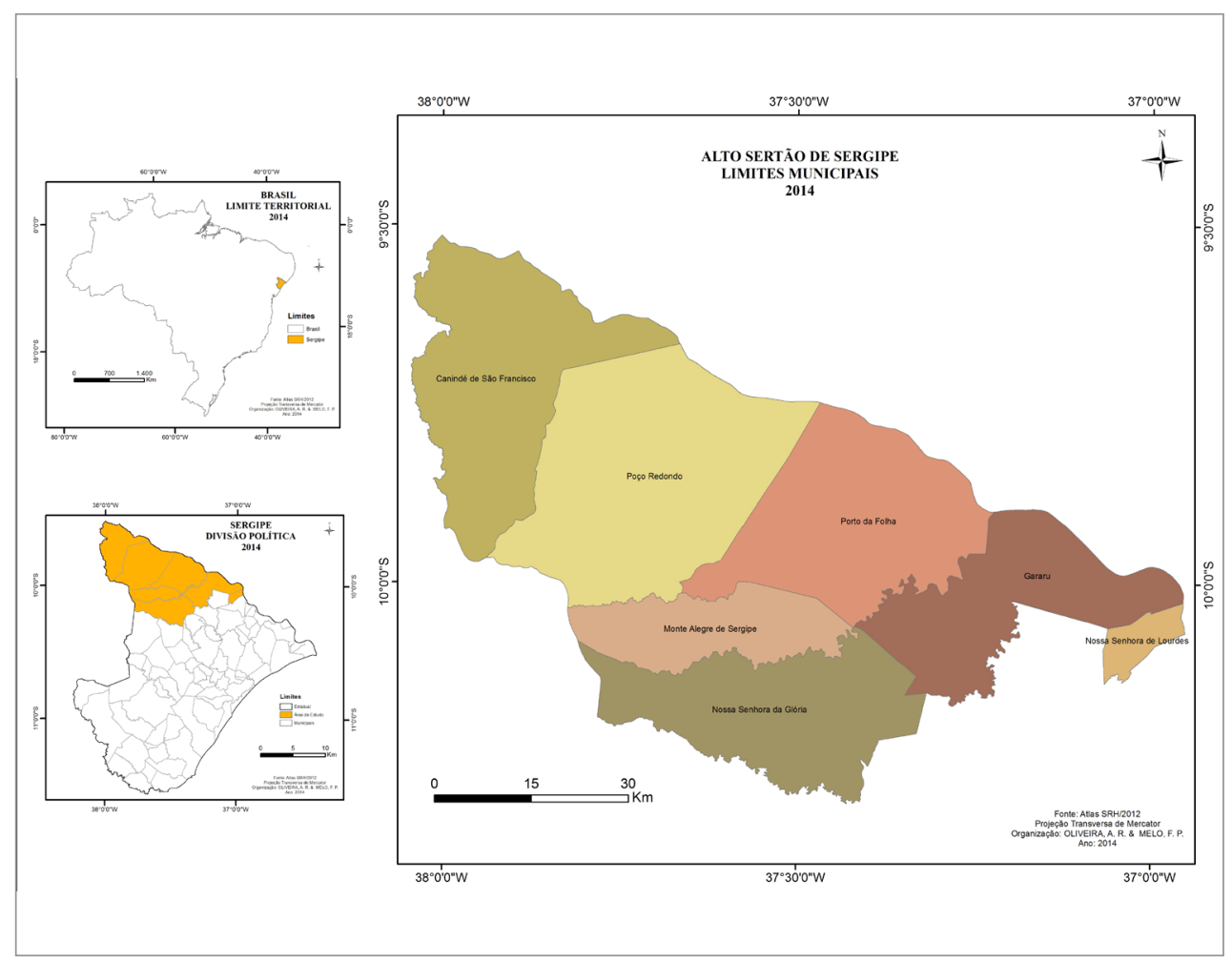

Fig. 1. Localização do Alto Sertão de Sergipe/BR Fonte: Atlas da SRH (2012)

Fig. 1. Location of Alto Sertão of Sergipe/BR Source: Atlas of SRH (2012)

Ademais, foi elaborado o climograma. Para construí-lo foi utilizada série histórica de precipitação do período de 1976 a 2008 disponibilizada pelo Centro de Meteorologia da SEMARH/SRH em Aracaju/SE (2015). Os dados foram armazenados no software Excel 2010 e a média mensal foi tabulada para posterior construção de gráficos e análise da área em estudo.

\section{RESULTADOS}

O Alto Sertão de Sergipe apresenta-se áreas com susceptibilidade a desertificação, com presença de formação de sulcos (Fig. 2) e ravinas (Fig. 3) provocada pela dinâmica natural dos sistemas e pelas derivações antropogênicas.
Os solos desnudos de vegetação tornam-se mais vulneráreis a degradação do solo, visto que a erosão hídrica e eólica promove uma remoção líquida de nutrientes levando o seu empobrecimento.

A figura 3 mostra outro processo de erosão que é a formação de ravina no município de Porto da Folha/SE.

Este processo de degradação ambiental pode evoluir para voçorocas à medida que se alargam e se aprofundam. Fullen e Catt (2004) diferenciam os dois processos, afirmando que, enquanto as ravinas tendem a fazer incisão, principalmente no horizonte $\mathrm{A}$, as voçorocas atingem facilmente os horizontes $\mathrm{B}$ e $\mathrm{C}$, podendo, por vezes, 


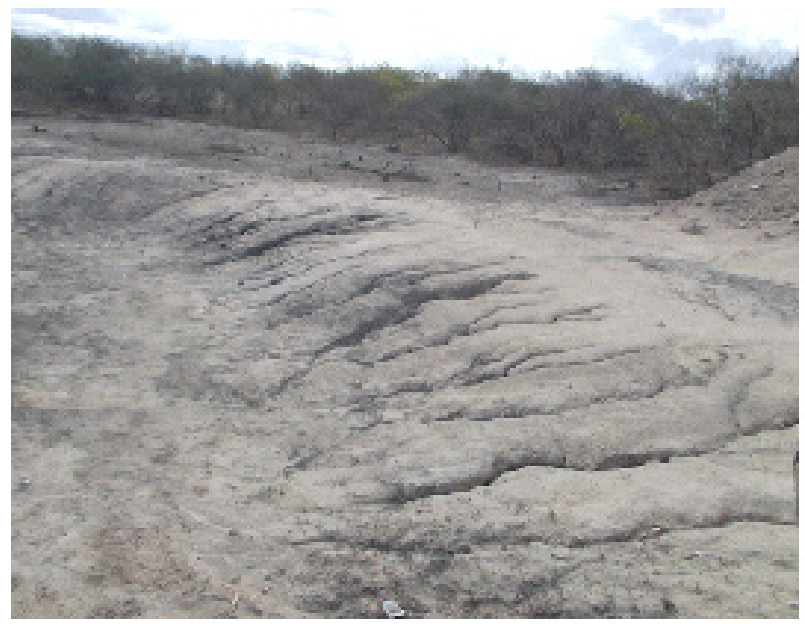

Fig. 2. Formação de sulcos no município de Poço Redondo/SE Fonte: Trabalho de campo, 2015.

Fig. 2. Formation of grooves in the municipality of Poço Redondo / SE Source: Work field, 2015.

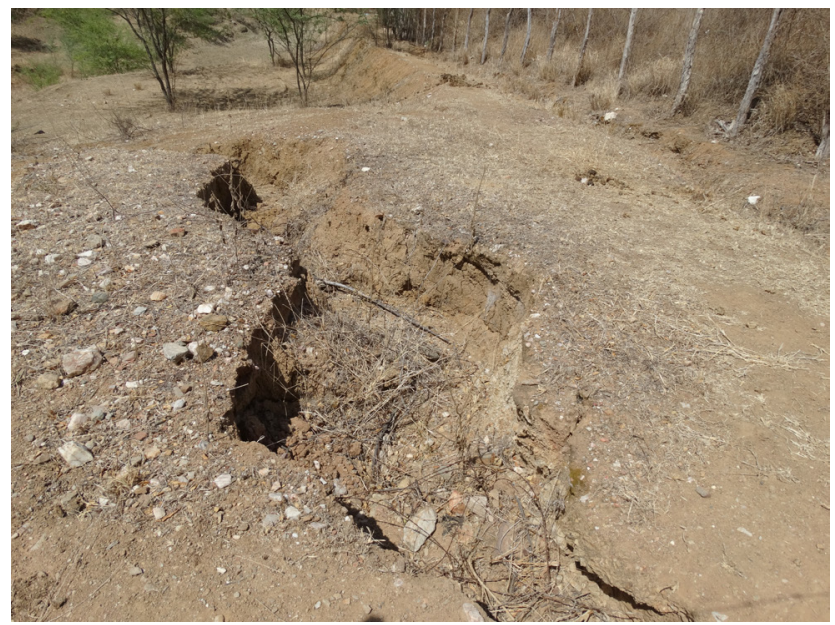

Fig. 3- Formação de ravina no município de Porto da Folha/SE Fonte: Trabalho de campo, 2015.

Fig. 3- Ravine formation in the city of Porto da Folha / SE Source: Work field, 2015.

chegar até a rocha matriz, dependendo da força do processo erosivo.

Destarte, a vegetação é um elemento importante para a proteção do solo, visto que reduz a intensidade de sulcos, ravinamentos e voçorocas, e por fim retalhamento do solo. Souza (2008) elucida que a retirada da vegetação é a ação mais comum que pode desencadear o processo de desertificação, e uma das consequências mais sérias está relacionada aos solos das regiões afetadas, 
em decorrência do aumento da erosão e os seus efeitos na fertilidade do solo.

As atividades como a agricultura, a pecuária e a mineração estão presentes no Alto Sertão de Sergipe. Estas, quando realizadas de forma inadequada poderão suscitar processos de desertificação.

A expansão do desmatamento do bioma caatinga modifica o sistema ambiental e provoca a supressão da microfauna no solo, redução de matéria orgânica, perda de solo, áreas improdutivas e o processo de migração. Essas transformações proporcionam conflitos socioambientais e criam novas dinâmicas na paisagem e nas apropriações da natureza e da sociedade.

Pinto \& Netto (2008) corroboram com estudiosos e pesquisadores ao definir que a derrubada da mata faz diminuir também o volume de pólens em suspensão na baixa troposfera, elementos que desempenhariam o papel de núcleos higroscópicos e estimulariam o processo de formação de nuvens, com reflexo para a atmosfera e para a superfície.

Os afloramentos rochosos estão presentes em todos os municípios, sendo que um dos fatores está relacionado à geologia da área, formada pelos domínios neoproterozóico a mesoproterozóico da Faixa de Dobramentos Sergipana que interfere na realização dos cultivos agrícolas.Os solos litólicos são rasos, susceptíveis a erosão, apresentando como principais limitações a rochosidade, a pedregosidade e o relevo acentuado que dificultam a penetração e a exploração de água e nutrientes pelas raízes de plantas. (Fig. 4)

Os processos naturais (relevo, solo, vegetação, clima e recursos hídricos) estão inter-relacionados formando um ciclo contínuo no sistema, pois quando há alteração entre os elementos compromete a funcionalidade e quebra o seu estado de

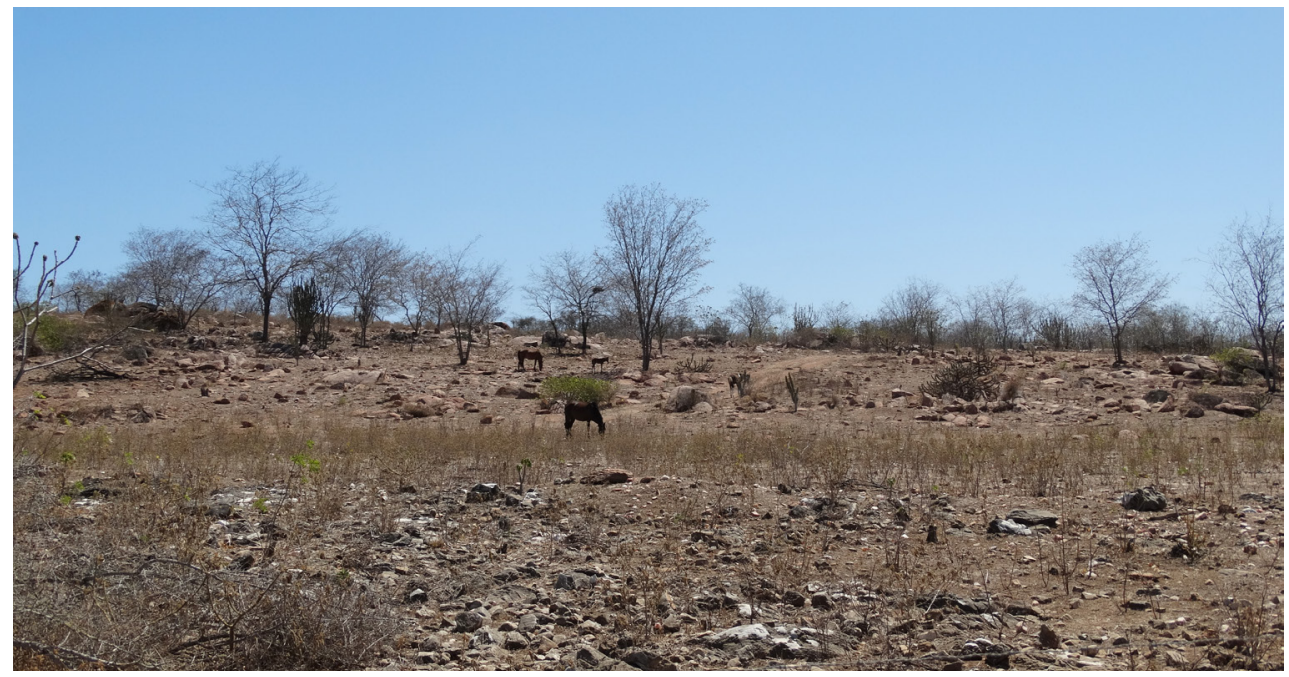

Fig. 4. Neossolo Litólico e afloramentos rochosos no município de Poço Redondo/SE

Fonte: Trabalho de campo, 2015.

Fig. 4. Littoral Neosol and rocky outcrops in the municipality of Poço Redondo / SE

Source: Work field, 2015. 
equilíbrio dinâmico (SPORL \& ROSS, 2004).

O clima é uma das variáveis relevantes na discussão dos problemas que suscitam a degradação ambiental e a possível desertificação no espaço semiárido do Alto Sertão Sergipano. Outros elementos naturais como o solo e a vegetação, bem como a influência da ação humana, a partir das atividades desenvolvidas no solo de forma inadequada, também contribuem para que ocorram desequilíbrios nos sistemas.

As chuvas no semiárido sergipano ocorrem de forma irregular em seus totais e em sua distribuição ao longo do ano, tendo um período seco de Primavera-Verão e um período chuvoso de Outono-Inverno, entre Abril e Agosto. A estação seca é de sete a oito meses e a chuvosa de cerca de quatro meses, o que contribui com a fragilidade dos sistemas naturais e socioeconômico. As precipitações pluviométricas médias anuais variam entre $368 \mathrm{~mm}$ e $630 \mathrm{~mm}$. A irregularidade de chuvas de um ano para o outro, o baixo índice de precipitação e a má distribuição durante o ano são características comuns da região. A figura 5 representa um climograma dos totais de chuvas do período de 1976 a 2008 dos municípios do Alto Sertão de Sergipe.

Ao analisar a figura 5, pode-se destacar que nesta série histórica de 1976 a 2008 os totais de chuvas dos municípios do Alto Sertão de Sergipe apresentaram máximos pluviais nos meses de Abril, Maio, Junho e Julho, pois nestes períodos acontece a realização dos cultivos agrícolas. Em Canindé de São Francisco e Poço Redondo existem o perímetro irrigado Jacaré-Curituba e Nova Califórnia e que não são dependentes dos elementos climáticos para a realização da lavoura, no entanto, não beneficia a todos igualmente. Os meses mais secos ocorrem entre Agosto e Março. É conveniente lembrar que tal comportamento é médio, devendo haver irregularidades na sua distribuição cronológica em períodos não muito bem definidos.

O quadro síntese foi elaborado a partir das observações em campo na área de estudo e revela os entrelaçamentos entre os fatores naturais (solo, chuva e vegetação) e antrópicos (cultivos, pecuária e estradas) e as respostas do sistema ambiente, integrados formam um sistema:

\begin{tabular}{|c|c|c|}
\hline TENSORES & IMPACTO AN & ANTAL / RESPOSTAS DO SISTEMA AMBIENTAL \\
\hline \multirow[b]{2}{*}{ NATURAIS } & Erosão do solo & Ganho e perda do solo; \\
\hline & Chuva & $\begin{array}{l}\text { Assoreamento de rios e reservatórios; } \\
\text { Formação de ravinas e voçorocas. }\end{array}$ \\
\hline \multirow{4}{*}{ ANTRÓPICOS } & Vegetação & $\begin{array}{l}\text { Desmatamentos } \\
\text { Aumento da erosão edáfica; } \\
\text { Desequilíbrio da fauna. }\end{array}$ \\
\hline & Cultivos & Uso de agrotóxico, poluição do solo, da água e do ar. \\
\hline & Pecuária & Compactação do solo \\
\hline & Mineração & Aceleração dos processos erosivos. \\
\hline
\end{tabular}

Trabalho de campo, 2014. 


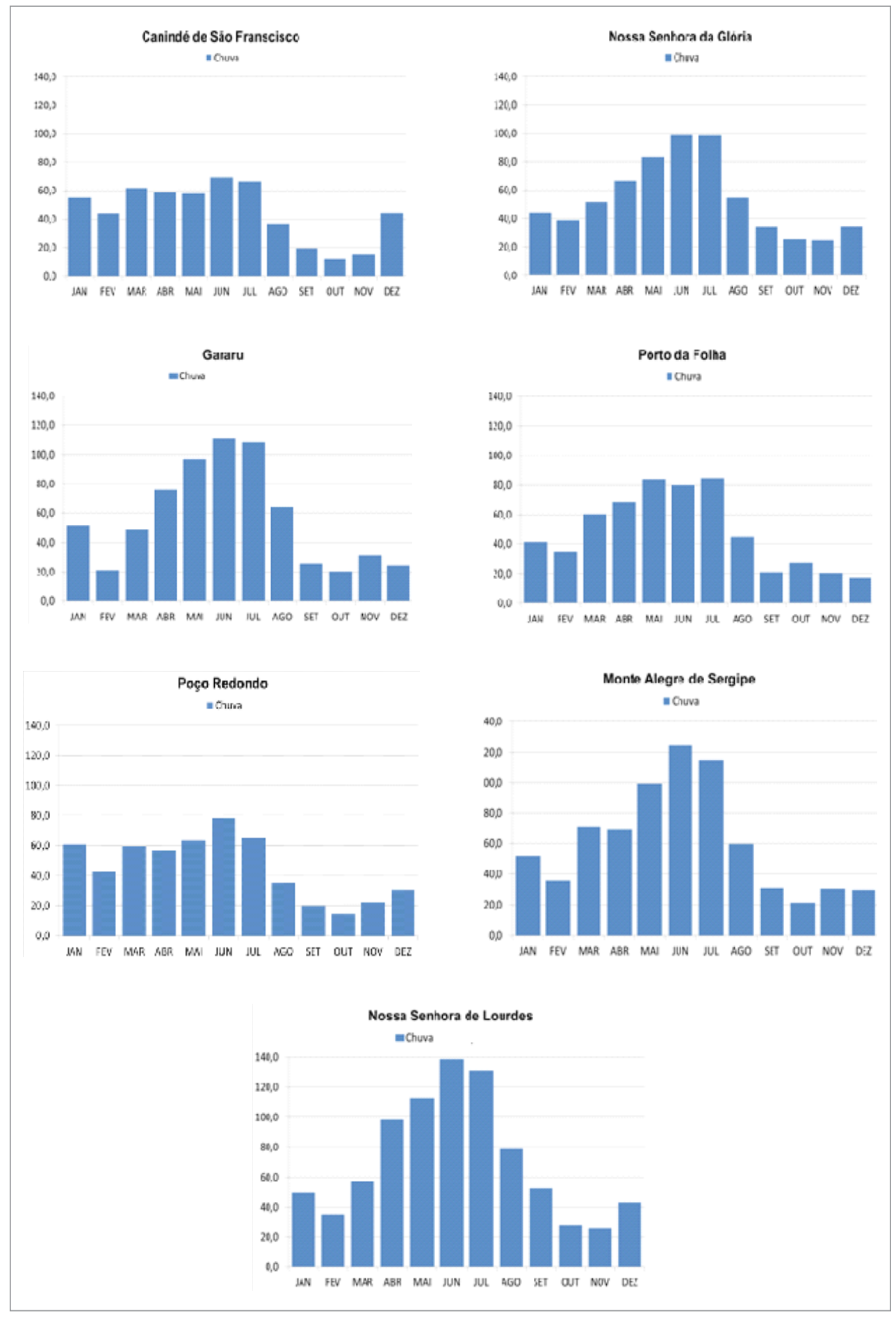

Fig. 5. Climograma dos municípios do Alto Sertão de Sergipe. Fonte: Centro de Meteorologia da SEMARH, 1976-2008

Fig. 5. Climograma the municipalities of Alto Sertão of Sergipe. Source: Weather Center SEMARH, 1976-2008 
O desmatamento é um dos indicadores para a aceleração dos processos erosivos, pois com a retirada da vegetação para a realização das atividades agropecuárias e mineração, o solo vai erodindo, podendo provocar impactos ambientais, como formação de ravinas e voçorocas; carreamento de sedimentos para cursos d'água; assoreamento de rios e reservatórios; desequilíbrio da fauna. Além disso, é de conhecimento público que a utilização de agrotóxicos nos cultivos agrícolas agride não somente o solo, mas também a água e o ar, pois é um sistema de imputs e outputs que influencia em todos os processos, seja natural, social e/ou econômico.

Outro exemplo são as gotículas de chuvas em solos desnudos durante um evento chuvoso, quando parte da água cai diretamente no solo, o processo de drenagem ocorre de forma mais rápida tendo uma perda considerável da superfície do solo, justificando assim, a formação de ravinas e voçorocas.

\section{CONCLUSÕES}

A desertificação é um processo dinâmico e está associada aos elementos naturais e antrogênicos da paisagem, evidenciada nos eco-geossistemas da área de estudo, como conexões entre sociedade e natureza.

Estudos individualizados e soluções diferenciadas são necessários em áreas susceptíveis à desertificação devido à diversidade dos ambientes naturais e dos fatores socioeconômicos de cada território para assim evitar ou minimizar os riscos e vulnerabilidades associados a esta problemática no Alto Sertão de Sergipe.

O reflorestamento e diminuição de pressão sobre a vegetação e o solo são intervenções relevantes para impedir que prejudiquem mais ainda o sistema socioambiental. Além disso, práticas sustentáveis devem ser incentivadas nos ambientes de clima seco para que possa ser evitada a criação e a expansão dos processos de desertificação.

\section{REFERÊNCIAS}

ALMEIDA, A.M. \& LIMA, E.N. (2001)

(Orgs.). De Sertões, Desertos e Espaços Incivilizados. Rio de Janeiro: FAPERJ: MAUAD.

\section{BATISTA, R.O.S.A. \& CONCEIÇÃO,} A. L. (2012). Estado, sociedade e educação pela natureza em J.J. Rousseau. IN: FONTENELE, A.C.F. et al. (Org). Reflexões sobre a relação sociedadenatureza na Geografia. Aracaju: Editora Diário Oficial.

BRASIL. MAPA. MMA. Ministério do Meio Ambiente/Secretaria de Recursos Hídricos (2005). PAN-Brasil: Programa de Ação Nacional de Combate à Desertificação e Mitigação dos Efeitos da Seca - edição comemorativa 10 anos da CCD. Brasília (DF).

CONTI, J.B. (1995). Desertificação nos trópicos: proposta de metodologia de estudo aplicada ao nordeste brasileiro. Tese de Livre Docencia - Departamento de Geografia, FFLCH, USP, Sao Paulo.

CUNHA, J.M.P., JACOB, A.A.E., HOGAN, D. J., \& CARMO, R.L. (2006). A vulnerabilidade social no contexto metropolitano: o caso de Campinas. In Cunha JMP. (Org). Novas metrópoles paulistas: população, vulnerabilidade e segregação. (pp. 143-68). Campinas: Editora da Unicamp.

FULLEN, M.A. \& CATT, J.A. (2004). Soil Management - Problems and Solutions. Arnold Publisher, Londres, Inglaterra. 
HOGAN, D. (2005). Mobilidade populacional, sustentabilidade ambiental e vulnerabilidade social. Revista Brasileira de Estudos da População. São Paulo, 22(2), 323-338.

LIMA, J.R., SUERTEGARAY, D.M.A., \& SANTANA, M.O. (2007). Desertificação e arenização. (192 p.). In SANTOS, R.F. Vulnerabilidade Ambiental. Brasília: MMA.

MENDONCA, F. A. (2010). Riscos e vulnerabilidades socioambientais urbanos A contingência climática. Mercator, 9 (1), 153-163.

NAVARRETE, D.M., GOMEZ, J.J., \& GALLOOPIN, G. (2007). Syndromes of sustainability of development for assessing the vulnerability of coupled human-environmental systems. The case of hydrometeorological disasters in Central America and the Caribbean. Global Environmental Change, 17(2), 207-217.

NIMER, E. (1980). Subsídio ao plano de ação mundial para combater a desertificação - Programa das Nações Unidas para o Meio Ambiente. Rev. Bras. Geogr. Rio de Janeiro, 42(3),612-637.
PINTO, J.E.S. de S. (2007). Climatologia sistemática. São Cristóvão: Universidade Federal de Sergipe, CESAD.

PINTO, J.E.S.de S. \& NETTO, A. de O.A. (2008). Clima, Geografia e Agrometeorologia: Uma abordagem Interdisciplinar. São Cristóvão: EditoraUFS.

SOUZA, B. I. (2008). Cariri paraibano: do silêncio do lugar à desertificação.Tese (Doutorado em Geografia) - Programa de Pós-Graduação em Geografia - Doutorado, UFRGS, Porto Alegre (RS).

SOUZA, M.J.N. (2000). Bases naturais e esboço do zoneamento geoambiental do estado do Ceará. In: SOUZA, M.J.N., MORAES J.O., \& LIMA, L. C. Compartimentação territorial e gestão regional do Ceará, Parte I. (pp.13-98). Fortaleza Editora FUNECE.

SPORL, C. \& ROSS, J.L.S. (2004). Análise comparativa da fragilidade ambiental com aplicação de três modelos. In.: GEOUSP - Espaço e Tempo, São Paulo, $15,39-49$.

TRICART, J. (1997). Ecodinâmica. (91p.). Rio de Janeiro, IBGE, Diretoria técnica, SUPREN. 